Article

\title{
Composition of a Soil Organic Carbon Increment under Different Vegetable Cultivation Patterns: A Study Using Three SOC Pools
}

\author{
Yang Liu ${ }^{1,2} \mathbb{D}$, Xiaoyu Liu ${ }^{3}$, Yanfang Feng ${ }^{4}$, Dongsheng Yu ${ }^{1, * \mathbb{D}}$ and Xuezheng Shi ${ }^{1}$ \\ 1 State Key Laboratory of Soil and Sustainable Agriculture, Institute of Soil Science, Chinese Academy of \\ Sciences, Nanjing 210008, China; luisyang@126.com (Y.L.); xzshi@issas.ac.cn (X.S.) \\ 2 Research Center of IoT Agriculture Applications, Institute of Agricultural Information, Jiangsu Academy of \\ Agricultural Sciences, Nanjing 210014, China; luisyang@126.com \\ 3 Jiangsu Vocational College of Agriculture and Forestry, Jurong 212400, China; liuxy0827@126.com \\ 4 Institute of Agricultural Resources and Environment, Jiangsu Academy of Agricultural Sciences, \\ Nanjing 210014, China; jaasfengyanfang@163.com \\ * Correspondence: dshyu@issas.ac.cn; Tel.: +86-025-8688-1272
}

Received: 27 November 2018; Accepted: 19 December 2018; Published: 21 December 2018

\begin{abstract}
Previous studies suggest that vegetable cultivation increases soil organic carbon (SOC) storage. However, how stable the SOC increment is, and how greenhouse cultivation contributes to the SOC increment in terms of quantity and stability, remains unclear. Soil samples were taken from three typical vegetable cultivation pattern fields: open field (OF), seasonal greenhouse (SG), and permanent greenhouse (PG), as well as adjacent non-vegetable fields. Three conceptual SOC pools, including active $\left(C_{a}\right)$, slow $\left(C_{s}\right)$, and resistant $\left(C_{r}\right)$ pools were fractionated to evaluate SOC sequestration and its stability in vegetable cultivation. The results indicate that vegetable cultivation is associated with greater stored SOC compared with non-vegetable cultivation (SOC increased by $57.9 \%$ on average). Using non-vegetable fields as a reference, SOC increments by vegetable cultivation were associated with a higher proportion of $C_{a}(3.7-6.6 \%)$ than the reference fields $(1.0-2.0 \%)$, indicating that the SOC increments might be easily decomposed. Among the three vegetable cultivation patterns, SG, with a higher increase in $C_{r}$, is recommended due to its relatively more stable SOC sequestration. Overall, vegetable cultivation could enhance the quantity of SOC, but the stability of the SOC increment is affected by the vegetable cultivation pattern.
\end{abstract}

Keywords: Open field; Greenhouse cultivation; Soil organic carbon pool; Vegetable cultivation

\section{Introduction}

The global soil organic carbon (SOC) pool is approximately $1500 \mathrm{Pg}$ (to 1 meter), which makes it the largest carbon pool in the terrestrial ecosystem [1,2]. Any small change in the SOC pool may greatly affect the atmospheric $\mathrm{CO}_{2}$ concentration. It has been suggested that land use/cover change (LUCC) is the main factor determining SOC storage [3,4]. Vegetable cultivation often requires more intensive management and larger inputs of nutrients and irrigation [5] compared to conventional cereal production. Therefore, conversion from non-vegetable fields (e.g., cereal fields) to vegetable cultivation is considered to be an important land use change that affects the SOC pool [6].

Vegetable cultivation in China has significantly increased in recent years because of high market prices and increasing demand [7]. The vegetable production of China accounted for about $51 \%$ of the global vegetable production [8]. In 2016, the area under vegetable production occupied approximately $13.4 \%$ of the overall agricultural land in China, which represented a dramatic increase of $2.2 \%$ from 1978, representing a total area of 22.3 million ha [9]. Further, besides conventional open field (OF) 
cultivation, vegetable cultivation patterns, such as seasonal and permanent greenhouses (SG and PG, respectively), developed rapidly. By 2010, the area of vegetable cultivation in greenhouses had increased to 3.4 million ha in China, accounting for $18 \%$ of the total area for vegetable cultivation in this country [10].

Previous research indicates that vegetable cultivation increases SOC. Kong et al. [11] found that the sequestration rates of surface SOC $(0-20 \mathrm{~cm})$ were 518 and $469 \mathrm{~kg} \mathrm{ha}^{-1} \mathrm{yr}^{-1}$ after conversion from rain-fed or irrigated land to open vegetable field, respectively. By comparing 20 sets of paired samples, Lei et al. [12] also found that conversion from cereal to greenhouse vegetable fields significantly increased the SOC content $\left(8.9 \mathrm{~g} \mathrm{~kg}^{-1}\right.$ in cereal grain fields versus $11.4 \mathrm{~g} \mathrm{~kg}^{-1}$ in greenhouse vegetable fields). Yan et al. [13] estimated that the accumulation rates of carbon in the surface soil $(0-30 \mathrm{~cm})$ of greenhouses' vegetable fields were, on average, $1.37 \mathrm{MgC} \mathrm{ha}^{-1} \mathrm{yr}^{-1}$ for a period of 8 years in North China by comparing paired soil samples from adjacent wheat-maize fields. Furthermore, based on the combination of data from both field observations and the literature, Wang et al. [14] concluded that the conversion from conventional vegetable cultivation (OF) to greenhouse vegetable cultivation could substantially enhance the carbon sink potential by 8.6 and 1.3 times for temperate and subtropical areas, respectively. However, total SOC content was not the only indicator for evaluating carbon sequestration in vegetable cultivation. If the increased $\mathrm{SOC}$ was easily decomposed to $\mathrm{CO}_{2}$, carbon sequestration in vegetable cultivation should be re-evaluated. Thus, stability of SOC should also be considered for a more comprehensive evaluation of SOC sequestrated in vegetable cultivation, which was ignored by most previous studies.

Carbon in soil is composed of a continuum of materials ranging in age from days for plant residues and root exudates to greater than 1000 years for resistant, humic substances [15]. To investigate the turnover of SOC, a number of models have been developed to fractionate SOC into different pools. For example, SOC was divided into active, slow, and resistant pools according to the mean residence time (MRT) in the Century Model $[16,17]$. Most researchers suggest that vegetable cultivation, especially greenhouse vegetable cultivation, increases the SOC content and benefits soil carbon sequestration. However, to be sequestered, carbon should be converted from active pools to less reactive intermediate or resistant pools [18] because resistant SOC generally has longer turnover times and the conversion provides information about the long-term potential for SOC sequestration [19].

Although vegetable cultivation probably increases the SOC content, it is still unclear how stable the resulting SOC increment is in terms of MRT of SOC fractions and how greenhouse cultivation contributes to SOC storage in quantity and stability compared with conventional open-field cultivation. Thus, for this study, a combination of acid hydrolysis and long-term laboratory incubation was introduced to fractionate SOC into three pools (active, slow, and resistant carbon) that have different MRTs. Vegetable fields under three main cultivation patterns, including open-field cultivation (OF), seasonal greenhouse (SG), and permanent greenhouse (PG) were selected. By comparing the SOC storage of vegetable fields (VFs) under different vegetable production patterns with that of adjacent non-vegetable reference fields (RFs), the effects of the cultivation patterns on SOC were evaluated.

The objectives of the present study were to (1) investigate the effects of different vegetable cultivation patterns on the quantity of the SOC pool; (2) investigate the effects of different vegetable cultivation patterns on the proportion of the three SOC pools; and (3) identify differences among the three vegetable cultivation patterns in the function of SOC sequestration as measured by both the quantity and stability of the SOC pool. 


\section{Materials and Methods}

\subsection{Study Area}

Cangshan County, where vegetable cultivation is the most popular form of agricultural production, is located in the south of Shandong Province $\left(34^{\circ} 37^{\prime}-35^{\circ} 06^{\prime} \mathrm{N}\right.$ and $117^{\circ} 41^{\prime}-118^{\circ} 18^{\prime} \mathrm{E}$, North China) and has a total area of $1800 \mathrm{~km}^{2}$. The climate is warm-temperate with periodic monsoon rain. The mean annual temperature is $13.2^{\circ} \mathrm{C}$, with the lowest of $-1.8^{\circ} \mathrm{C}$ in January. The mean annual precipitation is $860 \mathrm{~mm}$. The main soil types are fluvo-aquatic soil, cinnamon soil, and lime concretion black soil according to the Genetic Soil Classification of China (Ustochrepts, Hapludalfs, and Endoaquepts in the U.S. Soil Taxonomy, respectively, according to Shi et al. [20] and Yu et al. [20,21]), which support 34.4, 30.1, and 24.7\% of the total agricultural land, respectively [6]. Most agricultural area of Cangshan County was following a rotation of winter wheat and summer maize with limited irrigation and fertilizer input. However, currently, Cangshan County is famous as the southern vegetable garden of Shandong Province and uses diverse vegetable cultivation patterns. The three major vegetable cultivation patterns are open-field cultivation (OF), seasonal greenhouse (SG), and permanent greenhouse (PG). Open-field garlic cultivation has a history of up to 1000 years, and greenhouse vegetable cultivation was introduced to Cangshan County in the early 1980s. In 2010, vegetable land covered an area of 46,000 ha, with an annual yield of 2.25 million tons. OF, SG, and PG covered an approximate area of 290,90 , and $80 \mathrm{~km}^{2}$, respectively [22].

OF cultivation in Cangshan County mainly follows a rotation of garlic-maize. Only one vegetable season can be supported because of low fertilizer input and the sensitivity of crops to low temperatures in the open field compared with greenhouses. The SG pattern is almost the same as that of OF during summer, whereas agricultural plastic films are used to cover the cropped area in winter to minimize exposure to low temperatures. With seasonal greenhouses, an annual rotation may culminate in two or three harvests. PG is the most intensive vegetable cultivation pattern, with perennial coverage of plastic films. Vegetables can be continuously cultivated due to high fertilizer and irrigation inputs.

\subsection{Soil Sampling and Analysis}

Vegetable fields (VFs) under the three cultivation patterns and related reference fields (RFs) were sampled. The sampling sites of OF cultivation were located in Xihe village (lime concretion black soil), SG cultivation sites were located in Bulou village (lime concretion black soil), and PG cultivation sites were located in Xiecun village (fluvo-aquatic soil) (Figure 1). Xihe has a long history of garlic cultivation and is the main region for garlic production in China. The Bulou and Xiecun regions contain the largest concentration of land area under seasonal and permanent greenhouse vegetable production systems, respectively. The RF sampling plot in each site was selected based on an investigation from local farmers, where vegetable was never cultivated before. The VF sampling plots were selected based on a local soil map to ensure that sampling plots in each site shared the same soil type. 


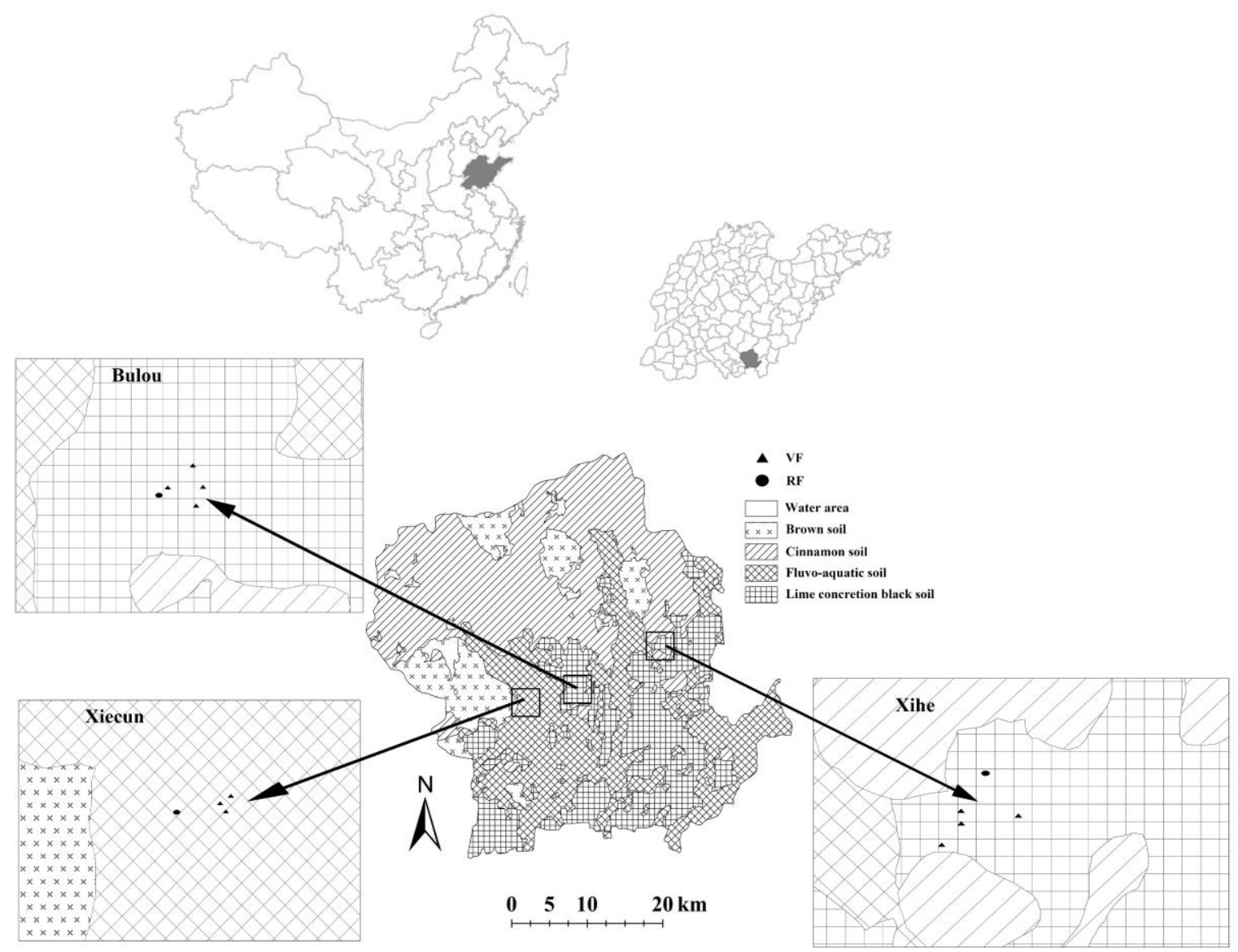

Figure 1. The location of the sampling sites of the vegetable fields (VFs) and their reference non-vegetable fields (RFs) in Cangshan County, China.

VFs conversion from RFs were selected for each cultivation pattern. A representative non-vegetable field adjacent to a corresponding vegetable field (ensuring that the sampling plots in each site shared the same soil type) was sampled as a reference for each vegetable cultivation pattern. In total, 14 plots were sampled in August of 2010. The details of the sampled sites are listed in Table 1.

Table 1. A description of the sampling sites in Cangshan County, China.

\begin{tabular}{|c|c|c|c|c|c|c|}
\hline \multirow{2}{*}{$\begin{array}{l}\text { Sampling } \\
\text { Site }\end{array}$} & \multirow{2}{*}{$\begin{array}{l}\text { Cultivation } \\
\text { Pattern }\end{array}$} & \multirow[t]{2}{*}{ n plots } & \multirow{2}{*}{$\begin{array}{c}\text { Vegetable } \\
\text { Rotation Type }\end{array}$} & \multirow{2}{*}{$\begin{array}{l}\text { Tillage Times } \\
\text { per Year }\end{array}$} & $\begin{array}{l}\text { Chemical } \\
\text { Fertilizer }\end{array}$ & $\begin{array}{c}\text { Organic } \\
\text { Fertilizer }\end{array}$ \\
\hline & & & & & \multicolumn{2}{|c|}{$\mathrm{tha}^{-1} \mathrm{yr}^{-1}$} \\
\hline \multirow{2}{*}{ Xihe } & Open field (OF) & 4 & garlic-maize & 1 & $0.7-1.5$ & $\begin{array}{l}0.8-1 \text { (Bean } \\
\text { cake) }\end{array}$ \\
\hline & $\begin{array}{l}\text { Reference field } \\
\qquad\left(\mathrm{RF}_{\mathrm{OF}}\right)\end{array}$ & 1 & wheat-maize & 1 & $<0.5$ & 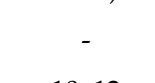 \\
\hline \multirow[t]{2}{*}{ Bulou } & $\begin{array}{c}\text { Seasonal } \\
\text { greenhouse (SG) }\end{array}$ & 4 & pepper-watermelon & $2-4$ & $1.1-1.5$ & $\begin{array}{c}10-12 \\
\text { (Chicken } \\
\text { manure) }\end{array}$ \\
\hline & $\begin{array}{l}\text { Reference field } \\
\qquad\left(\mathrm{RF}_{\mathrm{SG}}\right)\end{array}$ & 1 & wheat-maize & 1 & $<0.5$ & - \\
\hline \multirow[t]{2}{*}{ Xiecun } & $\begin{array}{c}\text { Permanent } \\
\text { greenhouse (PG) }\end{array}$ & 3 & cucumber-pepper & $2-4$ & $3-3.5$ & $\begin{array}{l}\text { 20-40 } \\
\text { (Chicken } \\
\text { manure) }\end{array}$ \\
\hline & $\begin{array}{l}\text { Reference field } \\
\quad\left(\mathrm{RF}_{\mathrm{PG}}\right)\end{array}$ & 1 & wheat-maize & 1 & $<1.0$ & (2) \\
\hline
\end{tabular}

In each plot with $4 \mathrm{~m} \times 5 \mathrm{~m}$ size, five surface soil $(0-20 \mathrm{~cm})$ samples were collected in an "S" pattern by a spade and mixed to form a composite sample, and $1 \mathrm{~kg}$ of fresh soil sample was taken to 
the laboratory. All samples were air-dried, and any visible living plant material or rocks were manually removed. Samples were broken down by a rubber pestle first and passed through a 2-mm sieve, then part of the samples were grinded by an agate mortar through a $0.149-\mathrm{mm}$ sieve for laboratory analysis. Particle-size distribution was determined by using the pipette method. Soil $\mathrm{pH}$ was determined by testing soil extract (1:2.5 soil/water ratio) with a $\mathrm{pH}$ meter. The Total SOC $\left(T_{S O C}\right)$ was determined by the $\mathrm{K}_{2} \mathrm{Cr}_{2} \mathrm{O}_{7}$ oxidation-titration method, available phosphorus (P) by the Olsen method, and available potassium (K) by a flame spectrometer [23]. Details on the laboratory analysis for the three SOC pools can be found in the Appendix A.

\subsection{Statistical Analysis}

Using the evolved $\mathrm{CO}_{2}$ as the input data, Equation (1) was fit with a non-linear regression that used the Marquardt algorithm and an iterative process to find the parameter values $\left(C_{a}, K_{a}\right.$, and $\left.K_{s}\right)$ with the minimum residual sum of squares [24]. Proportions of $C_{a}$ in the SOC increment $(\% \mathrm{Ca})$ after conversion from RF to VFs under different vegetable cultivation were calculated using Equation (1).

$$
\% C_{a}=\frac{C_{\text {aaverage }}-C_{a R F}}{S O C_{\text {average }}-S O C_{R F}}
$$

where $\% C_{a}$ represents proportions of $C_{a}$ in the SOC increment; $S O C_{\text {average }}$ and $C_{a}$ average represent the average SOC and $C_{a}$ in VFs under OF, SG, or PG cultivation; and $S O C_{R F}$ and $C_{a} R F$ represent the SOC and $C_{a}$ in the relative RFs. $\% C_{s}$ and $\% C_{r}$ were calculated using the same method. A t-test was performed to assess the differences of the soil properties between VFs and RFs. Variations of the soil properties between VFs and RFs were calculated first, and one-way ANOVA was used to compare the variations among different vegetable cultivation patterns. Multiple comparisons were performed by the least-significant difference method (LSD). In all analyses, a probability of error smaller than $5 \%$ ( $p<0.05)$ was considered significant. The SPSS analytical software package (Version 19.0, SPSS Inc., Chicago) was used for all of the statistical analyses.

\section{Results}

\subsection{Soil Properties}

The soil basic properties are described in Table 2. Soil texture varied for VFs and RFs under different cultivation patterns. The clay contents of OF and SG soils for VFs were 13.6 and $10.1 \%$ higher than those of RFs, respectively, whereas the sand contents were 9.2 and $10.6 \%$ lower than those of RFs, respectively. However, the clay and sand contents were not significantly different for PG.

Table 2. The surface soil properties of VFs (vegetable fields) and RFs (reference fields) in Cangshan County, China.

\begin{tabular}{|c|c|c|c|c|c|c|}
\hline \multirow{2}{*}{$\begin{array}{l}\text { Cultivation } \\
\text { Method }\end{array}$} & \multirow[t]{2}{*}{ sand } & silt & \multirow[t]{2}{*}{ clay } & \multirow{2}{*}{$\mathrm{pH}$} & Available P & Available K \\
\hline & & $\%$ & & & \multicolumn{2}{|c|}{$\mathrm{mg} \mathrm{kg}^{-1}$} \\
\hline $\mathrm{RF}_{\mathrm{OF}}{ }^{\mathrm{a})}$ & 22.1 & 47.9 & 30.0 & 6.4 & 24 & 104 \\
\hline OF & 12.9 & 43.5 & 43.6 & 7.6 & 13 & 176 \\
\hline One-sample $t$ test & ns & $*$ & ns & $*$ & ns & $*$ \\
\hline $\mathrm{RF}_{\mathrm{SG}}$ & 18.6 & 51.4 & 30.1 & 6.5 & 28 & 107 \\
\hline SG & 8.0 & 51.9 & 40.2 & 6.5 & 130 & 283 \\
\hline One-sample $t$ test & $*$ & ns & ns & ns & $*$ & $* *$ \\
\hline $\mathrm{RF}_{\mathrm{PG}}$ & 17.6 & 64.4 & 18 & 6.8 & 113 & 156 \\
\hline PG & 14.0 & 65.0 & 21.0 & 5.90 & 257 & 363 \\
\hline One-sample $t$ test & ns & ns & ns & ns & ns & ns \\
\hline
\end{tabular}

OF, SG, and PG represent open field, seasonal greenhouse, and permanent greenhouse, respectively. * significant at $\mathrm{p}<0.05 ;{ }^{* *}$ significant at $\mathrm{p}<0.01 ; \mathrm{ns}$, not significant for the t-test (the same below). a) Reference field. 
Soil nutrients of RFs varied among the three sampling sites. The available $\mathrm{P}$ and $\mathrm{K}$ of RF in Xiecun were 113 and $156 \mathrm{mg} \mathrm{kg}^{-1}$, respectively, which were much higher than those of Xihe and Bulou because of higher fertilizer use, as is local custom. The soil nutrients of VFs were higher than RFs for all three vegetable cultivation patterns mainly because of the excessive fertilizer and manure application. The increase of available $\mathrm{P}$ was $-11,102$, and $144 \mathrm{mg} \mathrm{kg}^{-1}$, while available $\mathrm{K}$ was 72 , 176, and $207 \mathrm{mg} \mathrm{kg}^{-1}$ for OF, SG, and PG, respectively. The soil nutrients increment in VFs generally followed the pattern OF $<$ SG $<$ PG (Table 2) in accordance with nutrient inputs for the different vegetable cultivation patterns (Table 1). Vegetable cultivation patterns have different effects on the soil properties and nutrients and further impact the SOC.

\subsection{SOC and SOC Pool Variations}

The SOC of RFs in the present study was only $6.4-7.7 \mathrm{~g} \mathrm{~kg}^{-1}$ (Figure 2a). However, after conversion to vegetable cultivation, the SOC notably increased by $57.9 \%$ on average $(4.3,5.2$, and $2.7 \mathrm{~g} \mathrm{~kg}^{-1}$ for OF, SG, and PG cultivation, respectively). Significant differences between VFs and RFs were observed for the OF and SG cultivation $(\mathrm{p}<0.05)$ (Figure 2a). Furthermore, the increment of SOC under SG was higher than that under OF and PG (Table 3), indicating that conversion from RF to SG cultivation could sequestrate more SOC.
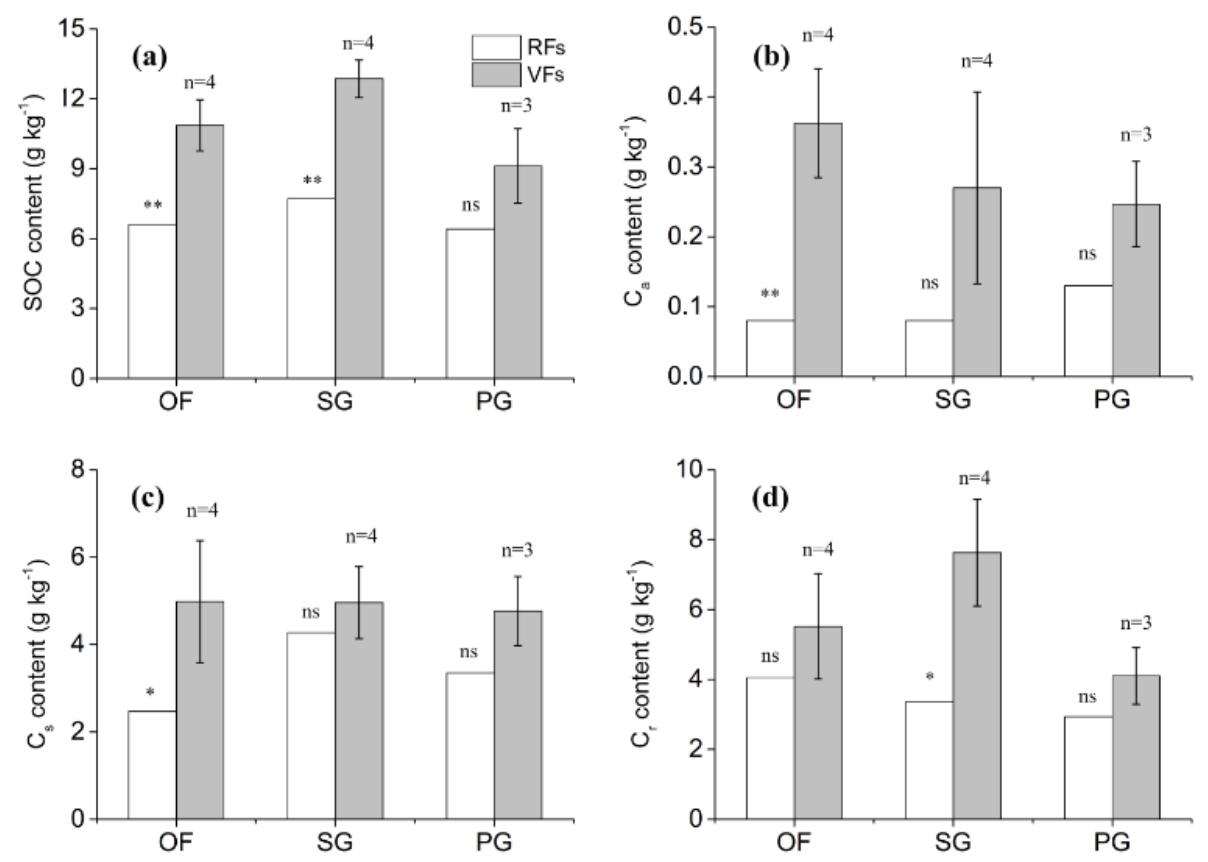

Figure 2. Surface soil organic carbon (SOC) content and fractionating SOC pools of the vegetable fields (VFs) and their reference non-vegetable fields (RFs) in Cangshan County, China. (a) SOC content; (b) Active SOC content; (c) Slow SOC content; (d) Resistant SOC content. The error bars represent standard deviations (the same below).

Fractionating SOC pools demonstrated that, compared with RFs, all of the SOC pools increased in VFs. However, significant differences were observed only in the $C_{a}$ and $C_{s}$ pools of $\mathrm{OF}$, and the $C_{r}$ pools of SG (Figure 2). The ANOVA results indicated that the increment of $C_{a}$ and $C_{r}$ under different vegetable cultivation showed limited or no differences, but $C_{r}$ under SG cultivation was significantly higher than that of OF and PG ( $\mathrm{p}<0.05)$ (Table 3). Most MRTs of $C_{a}$ and $C_{s}$ were longer in VFs compared with RFs, although the differences were not significant (Figure 3). 
Table 3. Variation of surface SOC content and fractionating SOC pools between the vegetable fields (VFs) and their reference non-vegetable fields (RFs) in Cangshan County, China. Different letters represent a significant difference $(\mathrm{p}<0.05)$.

\begin{tabular}{ccccc}
\hline Cultivation Pattern & SOC & $\mathbf{C}_{\mathbf{a}}$ & $\mathrm{C}_{\mathbf{s}}$ & $\mathrm{C}_{\mathbf{r}}$ \\
\cline { 2 - 5 } & \multicolumn{4}{c}{$\mathbf{g ~ k g ~ k}^{-\mathbf{1}}$} \\
\hline OF & $4.26 \pm 1.08 \mathrm{ab}$ & $0.28 \pm 0.08 \mathrm{a}$ & $2.52 \pm 1.40 \mathrm{a}$ & $1.47 \pm 1.51 \mathrm{~b}$ \\
SG & $5.15 \pm 0.82 \mathrm{a}$ & $0.19 \pm 0.14 \mathrm{a}$ & $0.69 \pm 0.82 \mathrm{~b}$ & $4.27 \pm 1.53 \mathrm{a}$ \\
PG & $2.71 \pm 1.63 \mathrm{~b}$ & $0.12 \pm 0.06 \mathrm{a}$ & $1.42 \pm 0.79 \mathrm{ab}$ & $1.17 \pm 0.81 \mathrm{~b}$ \\
Cultivation pattern & $\mathrm{ns}$ & $\mathrm{ns}$ & $\mathrm{ns}$ & $5.82^{*}$ \\
$(F$ value $)$ & & & & \\
\hline
\end{tabular}
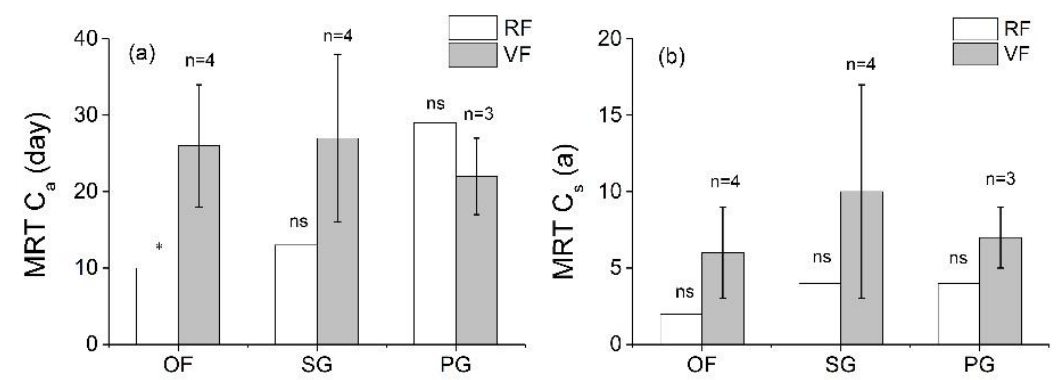

Figure 3. Mean residence times (MRTs) of the soil organic carbon pools of the vegetable fields (VFs) and reference non-vegetable fields (RFs) in Cangshan County, China. (a) MRT of Ca; (b) MRT of Cs.

\subsection{Proportions of SOC Increment}

After conversion to vegetable cultivation, SOC increased for all soil types (the increment was 4.3, 5.2 , and $2.7 \mathrm{~g} \mathrm{~kg}^{-1}$ for OF, SG, and PG cultivation, respectively). Using the paired non-vegetable plots as a reference, the $\mathrm{SOC}$ increment by vegetable cultivation was associated with a higher proportion of $C_{a}(6.6,3.7$, and $4.3 \%$ for OF, SG, and PG cultivation, respectively), compared with RFs $(1.0-2.0 \%)$. The proportion of $C_{s}$ and $C_{r}$ in the SOC increment was 59.0 and $34.4 \%$ and 52.4 and $43.3 \%$ for OF and PG cultivation, respectively, which were similar to or lower than the RFs (61.4 and $37.4 \%$ and 52.3 and $45.7 \%$, respectively). However, SOC sequestrated by SG cultivation was primarily associated with $C_{r}$ (an average increase of $4.3 \mathrm{~g} \mathrm{~kg}^{-1}$ ), while $C_{s}$ only increased by $0.7 \mathrm{~g} \mathrm{~kg}^{-1}$ (Figure 2). Therefore, among the three vegetable cultivation patterns, SG increased more SOC compared with PG cultivation. Further, the newly sequestrated SOC was more stable compared with that from the OF (Figure 4).

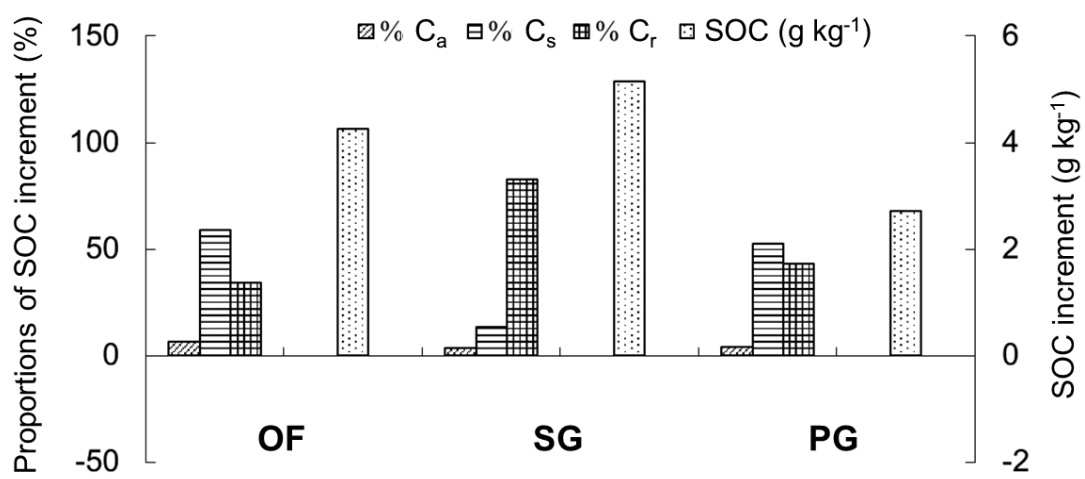

Figure 4. The SOC increment and its proportions of the active, slow, and resistant carbon pools from three vegetable cultivation patterns in Cangshan County, China. ${ }^{2} C_{a}, \% C_{s}$, and $\% C_{r}$ represent the increment proportions of the active, slow, and resistant carbon pools, respectively. 


\section{Discussion}

\subsection{SOC Increment Under Vegetable Cultivation}

Huang-Huai-Hai plain, where Cangshan County is located, is one of the most important crop production areas of China $[25,26]$. However, due to continuous production and tillage without enough nutrient input, the SOC of the cropland is usually at a low level. After conversion from crop to vegetable cultivation, SOC increased by $57.9 \%$ on average, which was greater than that after conversion from crop to greenhouse vegetable cultivation in a similar region (42.3\%) [13].

Soil organic carbon commonly declines in intensive cropping systems [27]. However, SOC increased with the agricultural land-use intensity (conversion from non-vegetable to vegetable field) in the present study. This increase of SOC mainly results from the increase of net primary productivity (an increasing amount of residues returned to the soil) and intensification of agricultural inputs: fertilizer, irrigation, and manure $[28,29]$. Large amounts of manure were utilized by vegetable cultivation in Cangshan County and offset greenhouse gases released from tillage or microbial decomposition [30,31]. Furthermore, studies have found a significant relationship between SOC and the clay content, because clay content could offer a chemical protection of SOC from microbial decay [32]. In the present study, OF and SG cultivation might increase the clay content, leading to an extra increase of SOC compared with PG. The clay content increased for two main reasons. First, the soil under OF and SG cultivation is lime concretion black soil, while the soil under PG cultivation is fluvo-aquatic soil. Based on a previous soil survey, lime concretion black soil has an excessive clay content. In contrast, fluvo-aquatic soil has a smaller clay content and is always used for intensive PG cultivation [33]. In addition to the soil type, the cultivation patterns may have an impact on the soil texture through an external input, e.g., irrigation from the sediment-laden water of the Yellow River could increase the clay content [34]. A local investigation revealed that a water-logged organic compost was applied to VFs to improve vegetable quality. The compost is a mixture of green manure with pond and river sediment that is rich in clay content. Thus, vegetable cultivation might increase the clay content. However, the clay content seems to accumulate more easily in the surface soil of lime concretion black soil than fluvo-aquatic soil because of the different soil texture [35]. Vegetable cultivation increased the SOC content; however, the characteristics of the SOC pools should be determined to evaluate their effects on SOC stability.

\subsection{SOC Pool Variations of the Increment}

The distributions of the three fractionating pools of SOC are distinctly different according to land use, primarily because the chemical components of vegetation vary greatly, resulting in unique effects on the SOC decomposition rate [36]. The active carbon pool accounted for 3.4, 2.2, and 2.7\% of the total SOC for VFs under OF, SG, and PG cultivation, respectively. The proportion was higher than that of forest soil, e.g., 0.4-1\% associated with a tree farm in Southern Appalachia [37] and 0.9-2.4\% for four types of forests in China [24], and was similar to that of agricultural land (1.2\% for paddy and $3.5 \%$ for upland) in mid-subtropical China [36]. Vegetable land is a specific agricultural land-use type consuming large amounts of fertilizer and manure. Chicken manure is the most popular manure type for vegetable cultivation in Cangshan County. As chicken manure has a fairly high decomposition rate [38], it might contribute to the high active carbon pool in SOC of vegetable land soils. The organic materials in forests decompose much more slowly than in agricultural land [36]. This can explain why the vegetable land acquires a higher proportion of $C_{a}$ than the forest soil.

\subsection{Effect of Vegetable Cultivation Pattern on the Stability of SOC}

Vegetable cultivation consumed large amounts of nutrients (Table 1) and resulted in the increase of both the yield and biomass. However, for vegetable production, SOC derived from crop residue is typically lower [39]. The SOC increment from vegetable cultivation was mainly from root residues (including exudates) and manure input $[13,40]$. These two sources of SOC are considered to decompose easily $[15,38]$ and have a high proportion of $C_{a}$. However, the quantitative contributions of 
biomass, root residues, and manure to the different SOC pools have not been discovered, and require further investigation.

In addition to the sources of the SOC increment, the environment of vegetable cultivation also had an impact on SOC stability. Greenhouse vegetable cultivation (especially PG) always maintains a high temperature and soil water content, accelerating the decomposition of SOC and release of $\mathrm{CO}_{2}$ to the atmosphere [41,42]. Therefore, PG demonstrates the shortest MRT of $C_{a}$ and the lowest SOC increment (Figures 3 and 4 ).

SG out-performed both OF and PG. The root residues and manure inputs of SG were higher than those of OF, whereas the MRT of both $C_{a}$ and $C_{s}$ were longer than those of PG (Figure 3). Thus, SG is considered to be the most beneficial cultivation pattern for increasing SOC sequestration in North China compared to the other patterns.

The present study was based on a spatial soil survey sampling. However, spatial distribution of sampling plots would introduce variance and uncertainty [43]. Therefore, more experimental plots should be conducted for more reliable results to investigate the effects of different vegetable cultivation patterns on SOC.

\section{Conclusions}

Vegetable cultivation significantly increased SOC compared with the reference non-vegetable fields, with vegetable fields under OF, SG, and PG cultivation increasing SOC by $4.3,5.2$, and $2.7 \mathrm{~g} \mathrm{~kg}^{-1}$, respectively (by $57.9 \%$ on average). Given the conversion from non-vegetable cultivation, vegetable fields could be a carbon sink and enhance the agricultural SOC storage. However, SOC stability was affected by the vegetable cultivation patterns. Using the paired non-vegetable fields as a reference, the SOC increment by vegetable cultivation was associated with a higher proportion of $C_{a}$, but a lower proportion of $C_{s}$ and $C_{r}$ compared with RFs. This result indicated that the SOC increment from vegetable cultivation might be not stable. Vegetable fields under SG cultivation are associated with a high vegetable output and stable SOC sequestration. SG cultivation is, therefore, preferred to balance the demands for both the environment and agriculture in the region. Our research results could provide a reference for studies in vegetable cultivation regions of North China.

Author Contributions: Conceptualization, D.Y. and Y.L.; methodology, Y.L.; formal analysis, X.L and F.Y.; writing (original draft preparation), Y.L., X.L., and F.Y.; writing (review and editing), Y.L., D.Y., and X.S.

Funding: This research was funded by the Natural Science Foundation of China, grant numbers 41571206 and 31800358; the Special project of the national key research and development program, grant number 2016YFD0200301; the Fund for Independent Innovation of Agricultural Sciences in Jiangsu Province, grant number CX(18)2029; and the Research Fund of State Key Laboratory of Soil and Sustainable Agriculture, grant number Y41220141.

Conflicts of Interest: The authors declare no conflict of interest.

\section{Appendix A Appendix}

Based on the first order kinetics equation (Equation (2)), SOC was fractionated into active, slow, and resistant pools [19].

$$
C_{\text {soct }}=C_{a} \times \exp \left(-K_{a} \times t\right)+C_{s} \times \exp \left(-K_{s} \times t\right)+C_{r} \times \exp \left(-K_{r} \times t\right)
$$

where $C_{\text {soct }}$ is the total organic carbon at time $t ; C_{a}$ and $C_{s}$ are the values of the active and slow pools; $K_{a}$, $K_{s}$, and $K_{r}$ are the decomposition rate constants for the active, slow, and resistant pools, respectively; and $C_{r}$ is the value of the resistant carbon pool as determined from the residue remnants of acid hydrolysis $[19,24]$. The value of $C_{S}$ is defined using Equation (3), with $T_{S O C}$ representing the total SOC. Therefore, the model estimates only three variables: $C_{a}, K_{a}$, and $K_{s}$.

$$
C_{\mathrm{s}}=T_{s o c}-C_{a}-C_{r}
$$


The MRT for each pool was calculated as the reciprocal of the decomposition rate constant $\left(K^{-1}\right)$ in the three-pool first-order model. The MRT of $C_{r}$ is commonly assumed to be 1000 years [19]. By converting Equations (4) and (5) to the passive pool MRT in the laboratory [44], we obtained $K_{r}=1 / M R T_{\text {lab }}$,

$$
\begin{gathered}
M R T_{\text {lab }}=M R T_{\text {field }} / Q_{10} \\
Q_{10}=2^{[(25-M A T) / 10]}
\end{gathered}
$$

where $M R T_{\text {lab }}$ represents the passive pool MRT in the laboratory; $M R T_{\text {field }}$ represents the passive pool MRT in the farmland; MAT is the mean annual temperature in the research area; and $Q_{10}$ is the temperature sensitivity coefficient, which is the increase in SOC decomposition that corresponds to each $10^{\circ} \mathrm{C}$ increase in the soil temperature [15].

To estimate the three variables and fractionate SOC among the active, slow, and resistant pools, patterns of carbon release from soil incubations were used [37]. For laboratory incubation, $100 \mathrm{~g}$ of each sample (passed through a 2-mm sieve) was incubated in 250-ml glass jars in the dark at $25^{\circ} \mathrm{C}$ with a $60 \%$ water holding capacity for 94 days. However, a large flush of $\mathrm{CO}_{2}$ evolved after rewetting the air-dried soils. The flush is the result of the decomposition of the microbial necromass present in dried soil and lysed by the rewetting process as well as the rapid growth of the microbial biomass in the new ideal environment [45]. Thus, samples were incubated for 7 days prior to analysis to remove the effect of the large flush of $\mathrm{CO}_{2}$ [46].

The water holding capacity was estimated by a volumetric soil water method. The jars were normally closed, but were opened periodically to maintain aerobic conditions. Water loss in the jars was monitored by weight and replenished after opening. No leaching occurred during the course of incubation. The evolved $\mathrm{CO}_{2}$ was trapped in $25 \mathrm{ml}$ of $0.4 \mathrm{~N} \mathrm{NaOH}$. A jar without soil was run simultaneously as a control. Evolved $\mathrm{CO}_{2}$ was precipitated by the addition of $\mathrm{BaCl}_{2}$ and measured by titration of residual $\mathrm{NaOH}$ to $\mathrm{pH} 7.0$ with $0.4 \mathrm{~N} \mathrm{HCl}$ [24]. The evolved $\mathrm{CO}_{2}$ was measured 12 times at $2,5,10,17,24,31,38,45,55,65,79$, and 94 days from the start of the incubation.

\section{References}

1. Batjes, N.H. Total carbon and nitrogen in the soils of the world. Eur. J. Soil Sci. 1996, 47, 151-163. [CrossRef]

2. Zhang, Z.Q.; Yu, D.S.; Wang, X.Y.; Pan, Y.; Zhang, G.X.; Shi, X.Z. Influence of the Selection of Interpolation Method on Revealing Soil Organic Carbon Variability in the Red Soil Region, China. Sustainability 2018, 10, 2290. [CrossRef]

3. Guo, L.B.; Gifford, R.M. Soil carbon stocks and land use change: A meta analysis. Glob. Chang. Biol. 2002, 8, 345-360. [CrossRef]

4. You, M.Y.; Burger, M.; Li, L.J.; Zou, W.X.; Li, N.; Qiao, Y.F.; Han, X.Z. Changes in Soil Organic Carbon and Carbon Fractions Under Different Land Use and Management Practices After Development From Parent Material of Mollisols. Soil Sci. 2014, 179, 205-210. [CrossRef]

5. Power, J.F.; Schepers, J.S. Nitrate contamination of groundwater in North-America. Agric. Ecosyst. Environ. 1989, 26, 165-187. [CrossRef]

6. Liu, Y.; Yu, D.S.; Wang, N.; Shi, X.Z.; Warner, E.D.; Zhang, H.D.; Qin, F.L. Impacts of agricultural intensity on soil organic carbon pools in a main vegetable cultivation region of China. Soil Tillage Res. 2013, 134, $25-32$. [CrossRef]

7. Cao, Z.H.; Huang, J.F.; Zhang, C.S.; Li, A.F. Soil quality evolution after land use change from paddy soil to vegetable land. Environ. Geochem. Health 2004, 26, 97-103. [CrossRef] [PubMed]

8. FAO. FAOSTAT Database-Resources, Food and Agriculture Organization of the United Nations; FAO: Rome, Italy, 2014.

9. National Bureau of Statistics of China. China Statistical Yearbook; China Statistics Press: Beijing, China, 2016. (In Chinese)

10. Guo, S.R.; Jin, S.; Sheng, S.; Lu, X.M.; Jin, T.; Wang, J.W. Analysis of general situation,characteristics,existing problems and development trend of protected horticulture in China. China Veg. 2012, 18. (In Chinese) 
11. Kong, X.B.; Zhang, F.R.; Wei, Q.; Xu, Y.; Hui, J.G. Influence of land use change on soil nutrients in an intensive agricultural region of North China. Soil Tillage Res. 2006, 88, 85-94. [CrossRef]

12. Lei, B.K.; Fan, M.S.; Chen, Q.; Six, J.; Zhang, F.S. Conversion of wheat-maize to vegetable cropping systems changes soil organic matter characteristics. Soil Sci. Soc. Am. J. 2010, 74, 1320-1326. [CrossRef]

13. Yan, Y.; Tian, J.; Fan, M.S.; Zhang, F.S.; Li, X.L.; Christie, P.; Chen, H.Q.; Lee, J.; Kuzyakov, Y.; Six, J. Soil organic carbon and total nitrogen in intensively managed arable soils. Agric. Ecosyst. Environ. 2012, 150, 102-110. [CrossRef]

14. Wang, Y.; Xu, H.; Wu, X.; Zhu, Y.M.; Gu, B.J.; Niu, X.Y.; Liu, A.Q.; Peng, C.H.; Ge, Y.; Chang, J. Quantification of net carbon flux from plastic greenhouse vegetable cultivation: A full carbon cycle analysis. Environ. Pollut. 2011, 159, 1427-1434. [CrossRef]

15. Collins, H.P.; Elliott, E.T.; Paustian, K.; Bundy, L.C.; Dick, W.A.; Huggins, D.R.; Smucker, A.J.M.; Paul, E.A. Soil carbon pools and fluxes in long-term corn belt agroecosystems. Soil Biol. Biochem. 2000, 32, 157-168. [CrossRef]

16. Kwon, H.Y.; Grunwald, S. Inverse modeling of $\mathrm{CO}_{2}$ evolved during laboratory soil incubation to link modeled pools in CENTURY with measured soil properties. Soil Sci. 2015, 180, 28-32. [CrossRef]

17. Parton, W.J.; Stewart, J.W.B.; Cole, C.V. Dynamics of C, N, P and S in Grassland Soils-A Model. Biogeochemistry 1988, 5, 109-131. [CrossRef]

18. Silveira, M.L.; Comerford, N.B.; Reddy, K.R.; Cooper, W.T.; El-Rifai, H. Characterization of soil organic carbon pools by acid hydrolysis. Geoderma 2008, 144, 405-414. [CrossRef]

19. Paul, E.A.; Morris, S.J.; Bohm, S. The Determination of Soil C Pool Sizes and Turnover Rates Biophysical Fractionation and Tracers; CRC Press: Boca Raton, FL, USA, 2001; pp. 193-206.

20. Shi, X.Z.; Yu, D.S.; Warner, E.D.; Sun, W.X.; Petersen, G.W.; Gong, Z.T.; Lin, H. Cross-reference system for translating between genetic soil classification of china and soil taxonomy. Soil Sci. Soc. Am. J. 2006, 70, 78-83. [CrossRef]

21. Yu, D.S.; Shi, X.Z.; Wang, H.J.; Sun, W.X.; Warner, E.D.; Liu, Q.H. National scale analysis of soil organic carbon storage in China based on Chinese soil taxonomy. Pedosphere 2007, 17, 11-18. [CrossRef]

22. Bureau of Changsha County. Cangshan Statistical Yearbook 2010; Shandong Statistics Press: Jinan, China, 2010. (In Chinese)

23. Lu, R. Soil Analytical Methods of Agronomic Chemistry; China Agricultural Science and Technology Press: Beijing, China, 1999. (In Chinese)

24. Yang, L.; Pan, J.; Shao, Y.; Chen, J.M.; Ju, W.M.; Shi, X.; Yuan, S. Soil organic carbon decomposition and carbon pools in temperate and sub-tropical forests in China. J. Environ. Manag. 2007, 85, 690-695. [CrossRef]

25. Cai, Z.C.; Qin, S.W. Dynamics of crop yields and soil organic carbon in a long-term fertilization experiment in the Huang-Huai-Hai Plain of China. Geoderma 2006, 136, 708-715. [CrossRef]

26. Shu, X.; Zhu, A.N.; Zhang, J.B.; Yang, W.L.; Xin, X.L.; Zhang, X.F. Changes in soil organic carbon and aggregate stability after conversion to conservation tillage for seven years in the Huang-Huai-Hai Plain of China. J. Integr. Agric. 2015, 14, 1202-1211. [CrossRef]

27. Halvorson, A.D.; Wienhold, B.J.; Black, A.L. Tillage, nitrogen, and cropping system effects on soil carbon sequestration. Soil Sci. Soc. Am. J. 2002, 66, 906-912. [CrossRef]

28. Puget, P.; Lal, R. Soil organic carbon and nitrogen in a Mollisol in central Ohio as affected by tillage and land use. Soil Tillage Res. 2005, 80, 201-213. [CrossRef]

29. Wang, X.Z.; Zou, C.Q.; Gao, X.P.; Guan, X.L.; Zhang, W.S.; Zhang, Y.Q.; Shi, X.J.; Chen, X.P. Nitrous oxide emissions in Chinese vegetable systems: A meta-analysis. Environ. Pollut. 2018, 239, 375-383. [CrossRef] [PubMed]

30. Yu, D.S.; Yang, H.; Shi, X.Z.; Warner, E.D.; Zhang, L.M.; Zhao, Q.G. Effects of soil spatial resolution on quantifying $\mathrm{CH}_{4}$ and $\mathrm{N}_{2} \mathrm{O}$ emissions from rice fields in the Tai Lake region of China by DNDC model. Glob. Biogeochem. Cycle 2011, 25. [CrossRef]

31. Yu, D.S.; Zhang, L.M.; Shi, X.Z.; Warner, E.D.; Zhang, Z.Q.; Zhao, Q.G. Soil Assessment Unit Scale Affects Quantifying CH4 Emissions from Rice Fields. Soil Sci. Soc. Am. J. 2013, 77, 664-672. [CrossRef]

32. Bell, M.J.; Worrall, F. Estimating a region's soil organic carbon baseline: The undervalued role of land-management. Geoderma 2009, 152, 74-84. [CrossRef]

33. Bureau of Cangshan County. The Soils of Cangshan County; Office of Soil Survey in Shandong Province: Jinan, China, 1983. (In Chinese) 
34. Dong, L.L.; Yu, D.S.; Zhang, H.D.; Zhang, M.L.; Jin, W.H.; Liu, Y.; Shi, X.Z. Long-term effect of sediment laden Yellow River irrigation water on soil organic carbon stocks in Ningxia, China. Soil Tillage Res. 2015, 145, 148-156. [CrossRef]

35. Aggelides, S.M.; Londra, P.A. Effects of compost produced from town wastes and sewage sludge on the physical properties of a loamy and a clay soil. Bioresour. Technol. 2000, 71, 253-259. [CrossRef]

36. Iqbal, J.; Hu, R.G.; Lin, S.; Ahamadou, B.; Feng, M.L. Carbon dioxide emissions from Ultisol under different land uses in mid-subtropical China. Geoderma 2009, 152, 63-73. [CrossRef]

37. Chapman, S.K.; Palanivel, R.U.; Langley, J.A. Soil carbon stability responds to land-use and groundcover management in southern appalachian agroecosystems. Soil Sci. Soc. Am. J. 2012, 76, 2221-2229. [CrossRef]

38. Liu, Z.H.; Jiang, L.H.; Zhang, W.J.; Zheng, F.L.; Wang, M.; Lin, H.T. Evolution of fertilization rate and variation of soil nutrient contents in greenhouse vegetable cultivation in Shandong. Acta Pedol. Sin. 2008, 45, 296-303. (In Chinese)

39. Pinheiro, E.F.M.; Pereira, M.G.; Anjos, L.H.C. Aggregate distribution and soil organic matter under different tillage systems for vegetable crops in a Red Latosol from Brazil. Soil Tillage Res. 2004, 77, 79-84. [CrossRef]

40. Erich, M.S.; Plante, A.F.; Fernandez, M.; Mallory, E.B.; Ohno, T. Effects of profile depth and management on the composition of labile and total soil organic matter. Soil Sci. Soc. Am. J. 2012, 76, 408-419. [CrossRef]

41. Arevalo, C.B.M.; Chang, S.X.; Bhatti, J.S.; Sidders, D. Mineralization potential and temperature sensitivity of soil organic carbon under different land uses in the Parkland Region of Alberta, Canada. Soil Sci. Soc. Am. J. 2012, 76, 241-251. [CrossRef]

42. Rovira, P.; Vallejo, V.R. Labile and recalcitrant pools of carbon and nitrogen in organic matter decomposing at different depths in soil: An acid hydrolysis approach. Geoderma 2002, 107, 109-141. [CrossRef]

43. Lark, R.M.; Marchant, B.P. How should a spatial-coverage sample design for a geostatistical soil survey be supplemented to support estimation of spatial covariance parameters? Geoderma 2018, 319, 89-99. [CrossRef]

44. Qian, H.Y.; Pan, J.J.; Sun, B. The relative impact of land use and soil properties on sizes and turnover rates of soil organic carbon pools in Subtropical China. Soil Use Manag. 2013, 29, 510-518. [CrossRef]

45. Clark, J.D.; Plante, A.F.; Johnson, A.H. Soil organic matter quality in chronosequences of secondary northern hardwood forests In western New England. Soil Sci. Soc. Am. J. 2012, 76, 684-693. [CrossRef]

46. Franzluebbers, A.J.; Haney, R.L.; Honeycutt, C.W.; Schomberg, H.H.; Hons, F.M. Flush of carbon dioxide following rewetting of dried soil relates to active organic pools. Soil Sci. Soc. Am. J. 2000, 64, 613-623. [CrossRef]

(C) 2018 by the authors. Licensee MDPI, Basel, Switzerland. This article is an open access article distributed under the terms and conditions of the Creative Commons Attribution (CC BY) license (http:/ / creativecommons.org/licenses/by/4.0/). 